\title{
INGUINAL HERNIA MESHPLASTY USING LOCAL ANAESTHESIA- CURRENT OPTIONS IN A RURAL HOSPITAL: A REVIEW OF 96 CASES
}

\author{
P. Deori1, Pranjit Deka² \\ ${ }_{1}^{1}$ Assistant Professor, Department of Surgery, Tezpur Medical College and Hospital, Tezpur, Assam. \\ ${ }^{2}$ Assistant Professor, Department of Surgery, Tezpur Medical College and Hospital, Tezpur, Assam.
}

\begin{tabular}{l} 
ABSTRACT \\
\hline BACKGROUND \\
Groin hernia is one of the most common surgical problems in male. Its treatment is always surgical if not contraindicated \\
otherwise. For many years, inguinal hernia surgery has been carried out under general or spinal anaesthesia. But in recent years \\
more and more emphasis is given on repair under local anaesthesia even when GA or SA is contraindicated. It is cost effective, only \\
fear of intraoperative pain hinders its widespread use.
\end{tabular}

\section{OBJECTIVE}

To evaluate the feasibility, operative and postoperative complications of inguinal hernia mesh repair under local anaesthesia and its safety and effectiveness in a rural teaching hospital.

\section{METHODS}

This prospective study was carried out in a Surgical Dept. of a teaching rural hospital in Assam from Jan/2014 to Dec/2015 in total 96 male patients, irrespective of age groups from 20 yrs. to 75 yrs. Hernia direct or indirect and reducible, complete or incomplete were included. Exclusion criteria- Obstructed, irreducible, strangulated hernias excluded. All the standard procedure recommended for open technique with polypropylene mesh were followed, only hernia site were infiltrated with L/A. Patients were put under observation during intraop and postop. Pain, vomiting, hypotension, urinary retention and wound haematoma and total hospital stay.

\section{RESULTS}

Total 96 male patients were included in the study. Mean age was 46.2 yrs. Out of these 72 (75\%) were I. I. Hernia variety and 24 (25\%) were Direct variety. In our study, 23 (24\%) patients had minor problems during intraop period. During postop period, 21 (21.8\%) patients developed operative site pain. Haematoma was seen in $4(4.1 \%)$ patients.

\section{CONCLUSION}

Tension-free meshplasty under L/A is simple, safe, cost-effective, very low rate of complications, quick recovery, early discharge from hospital and feasible alternative in a rural hospital.

\section{KEYWORDS}

Groin hernia, Mesh Hernioplasty, Local Anaesthesia.

HOW TO CITE THIS ARTICLE: Deori P, Deka P. Inguinal hernia meshplasty using local anaesthesia-current options in a rural hospital: a review of 96 cases. J. Evolution Med. Dent. Sci. 2016;5(30):1564-1567, DOI: 10.14260/jemds/2016/368

\section{INTRODUCTION \\ Inguinal hernia repair, one of the most commonly performed operation in Gen. Surgery and also one of the oldest surgical disease ever described in Surgery. ${ }^{1}$ Inguinal hernia repair can be done under G/A, S/A and L/A. ${ }^{2}$ The choice of anaesthesia is under debate. But the most commonly performed under S/A. Recently more emphasis is given on local anaesthesia. Patient's safety and optimum operating condition for surgeon are the two main criteria for choice of anaesthesia in inguinal hernia repair. S/A and G/A causes haemodynamic changes and has inherent related complications during induction and maintenance. ${ }^{3}$ The use of $\mathrm{L} / \mathrm{A}$ varies countries to countries, e.g. Denmark-18\%, Shouldice Clinic, Toronto Clinic, etc. almost $100 \%{ }^{4}$}

Financial or Other, Competing Interest: None.

Submission 09-03-2016, Peer Review 21-03-2016,

Acceptance 24-03-2016, Published 14-04-2016.

Corresponding Author:

Dr. P. Deori,

Assistant Professor, Department of Surgery,

Tezpur Medical College Hospital,

Tezpur, Assam.

E-mail: deoripddr@gmail.com

DOI: $10.14260 /$ jemds/2016/368
Local anaesthesia found to be best anaesthesia for hernia repair in these countries. In our countries, mostly S/A or G/A are used. Studies comparing the recovery profile among $\mathrm{L} / \mathrm{A}$, G/A and S/A; L/A is best for day care surgeries. ${ }^{5} \mathrm{~L} / \mathrm{A}$ provides increased safety for patients, better postop pain control, shorter recovery period with reduced hospital stay, reduced cost. ${ }^{4}$ Hence, L/A is acceptable and safe technique for inguinal hernia repair. $6,7,8,9,10,11,12$

The aim of this study to evaluate the above advantages by utilising this technique in all our inguinal hernia patients who met the inclusion criteria.

\section{MATERIAL AND METHODS}

Basic principle followed - "DO NO HARM TO PATIENT." This prospective study was carried out in a Teaching Rural Hospital at Tezpur, Assam, for the period of 2 yrs. from 1 st Jan/2014 to Dec/2015. This study included 96 cases of inguinal hernia having age groups between 20 yrs. to 70 yrs. repaired under L/A. After admission, detailed history taken and thorough clinical examination done. Lab Investigations-Hb\%, TC, DLC, ESR, RBS, Blood Urea, S. Creatinine, CXR, ECG, Viral Profile, etc. done.

Only male patient with inguinal hernia which were reducible, direct or indirect were included in the study. 
Exclusion criteria was female patient, rec. hernia, huge hernia, obstructed hernia, strangulated hernia, incarcerated hernia, sliding hernia, bilat. hernia, cardiac or renal failure or patients having chronic debilitating disease.

For all patients preop. Antibiotics $3^{\text {rd }}$ gen. cephalosporins single dose were used just before operations. Operative area shaved, IV line maintained. Local anaesthesia technique comprised infiltration and nerve block. Lignocaine in the concentration of $0.5 \%$ with adrenaline $(1: 200000)$ and Inj. Bupivacaine in $0.25 \%$ concentration was used in all cases. L/A was given within the safe dose (i.e. Lig. with adrenaline safe dose is $7 \mathrm{mg} / \mathrm{kg}$ ). By using small bore needle of 22 gauge, three skin wheals were raised-1. $3 \mathrm{~cm}$ medial to a line joining anterior superior iliac spine and umbilicus, 2. Directly over pubic tubercle, and 3. Over the deep inguinal ring - $1-2 \mathrm{~cm}$ above the mid-point of the inguinal ligament.

By using 22 gauge needle, $5 \mathrm{~mL}$ solution was injected subcutaneously between wheal 1 and ant. sup. iliac spine. Three doses of $10 \mathrm{~mL}$ solution given in a fan shaped in the transverse plane were injected deep to extl. oblique aponeurosis (Total $35 \mathrm{~mL}$ ) through wheal 2, $5 \mathrm{~mL}$ solution was injected directly on to the pubic tubercle, a further $5 \mathrm{~mL}$ lateral to the pubic tubercle at a depth of $3 \mathrm{~cm}$ and further $10 \mathrm{~mL}$ subcutaneously towards the umbilicus for a distance $8 \mathrm{~cm}$ (Total vol. Solution: $55 \mathrm{~mL}$ ). Through wheal 3, needle was passed perpendicularly backward to penetrate ext. oblique aponeurosis, $20 \mathrm{~mL}$ of solution injected in the line inguinal ligament (Total vol. $75 \mathrm{~mL}$ ). Next, $10 \mathrm{~mL}$ of solution was injected subcutaneously in the line of skin incision. During dissection of sac, if pain felt by the patient due to peritoneal traction, little amount L/A can be injected in neck of the sac.

Tension free Lichtenstein meshplasty was done maintaining standard operative procedure using standard polypropylene mesh. After surgery, the patient was shifted to the ward, where he was monitored for postop site pain, vomiting, hypotension, wound haematoma and urinary retention every hour for 6 hours and then six-hourly till the time of discharge. No statistical test was applied for any comparison.

\section{RESULT}

All the 96 patients studied were male. The age ranges from 20 yrs. to 70 yrs. The mean age was 46.2 yrs. The incidence of indirect inguinal hernia was higher than the D.I. hernia. The indirect variety was 72 (75\%), while the direct variety was 24 (25\%) patients. Age of indirect variety were from 20 yrs. to 44 yrs. and in the direct variety between 50 to 70 yrs. (Table I). Rt. side variety was $69(71.8 \%)$ and Lt. side variety was 27 (28.2\%). Most of the hernia were spontly. reducible variety 68 (69.7\%) and only few 28 (29.1\%) were manually reducible.

In our study $19(20.8 \%)$ patients had minor operative complications during the procedure. Out of these 17 (17.7\%) had mild pain, 3 (3.1\%) had vomiting, while 1 (1.04\%) had developed hypotension. All the problems were successfully managed. Complications were studied in terms of early postop (Within $6 \mathrm{hrs}$.) and late phases at the time of discharge. Out of total 96 patients, 27 (28.1\%) developed wound pain.

Out of these, 16 (59.3.2\%) were early phase and 11 $(40.7 \%)$ were in the late phase, those would be managed simply using NSAID. Haematoma developed in $4(4.2 \%)$ cases, where $1(25 \%)$ in early phase and $3(75 \%)$ in the late phase. They could also be managed conservatively. Vomiting 2
$(100 \%)$ in early phase and no late phase vomiting recorded, while $1(1.04 \%)$ developed hypotension. Urinary retention in $1(1.04 \%)$ patient in the early phase. Wound infection in 2 $(2.08 \%)$ patients in the late phase (Table 2). Maximum patients around $80(83.3 \%)$ could take liquid orally and mild physical activities such as going to toilet, etc. could do within 6 hrs. Delay of physical activity was due to fear of pain.

Postop hospital stay ranged from 1 day to 3 days. Out of total 96 patients, $58(60.41 \%)$ were kept for one day, 23 (23.9\%) were kept for 2 days and only 15 (15.6\%) were kept for 3 days. The mean hospital stay was 1.6 days.

\begin{tabular}{|c|c|c|c|}
\hline Side & Direct (n=24) & Indirect (n=72) & Total \\
\hline Right & $17(70.83 \%)$ & $58(80.5 \%)$ & $69(71.8 \%)$ \\
\hline Left & $7(29.16 \%)$ & $14(19.4 \%)$ & $27(28.2 \%)$ \\
\hline \multicolumn{4}{|c|}{ Table 1: Type of Hernia } \\
\hline
\end{tabular}

\begin{tabular}{|c|c|c|c|}
\hline & $\begin{array}{c}\text { Early } \\
\text { Phase }\end{array}$ & $\begin{array}{c}\text { Late } \\
\text { Phase }\end{array}$ & Total \\
\hline Wound Pain & $16(59.3 \%)$ & $\begin{array}{c}11 \\
(40.7 \%)\end{array}$ & $\begin{array}{c}27 \\
(28.1 \%)\end{array}$ \\
\hline Haematoma & $1(25 \%)$ & $3(75 \%)$ & $4(4.2 \%)$ \\
\hline Hypotension & $1(100 \%)$ & 0 & $1(1.04 \%)$ \\
\hline Vomiting & $2(100 \%)$ & 0 & $2(2.08 \%)$ \\
\hline $\begin{array}{c}\text { Urinary } \\
\text { retention }\end{array}$ & $1(100 \%)$ & 0 & $1(1.04 \%)$ \\
\hline $\begin{array}{c}\text { Wound } \\
\text { Infection }\end{array}$ & 0 & $3(100 \%)$ & $3(3.15 \%)$ \\
\hline \multicolumn{4}{|c|}{ Table 2: Post-operative Complications (n=96) } \\
\hline
\end{tabular}

\section{DISCUSSION}

Since Bassini's repair various other methods of hernia repair have been discussed. The ideal method is that cause minimal discomfort to the patient, technically simple, low cost, low rate of complications and most importantly low recurrence rate. ${ }^{13,14}$ The Bassini (Non-Anatomical) repair or Shouldice (Anatomical) repair practiced till today has recurrence rate of 1 to $6 \%$, may be due to tension in suture line.15,16 The use of prosthetic mesh allows tension free repair and very low recurrence rate. 17

The prevalence of hernia is common in middle and old age. 18 In this study, the age range from 20 yrs. to $70 \mathrm{yrs}$. and the mean age was $46.2 \mathrm{yrs}$. Kark A E et al. (1998). ${ }^{19}$ showed age group between 15 to $92 \mathrm{yrs}$., Song et al. (2009). ${ }^{20}$ showed mean age 42 yrs. operated under L/A and $86 \%$ male and 14\% were female. Ryan et al. (1984). ${ }^{21}$ Young D V (1987). ${ }^{15}$ and Erdem et al.22 also showed similar results. In our studies same age groups, but $100 \%$ male.

Present studies 72 (75\%) had I. I. hernia and 24 (25\%) had direct hernia. It is similar to other studies. ${ }^{9,18,21,23}$ Similarly, Rt. sided variety were 69 (71.8\%) and Lt. sided variety were $27(28.15 \%)$, which is comparable to other studies. $^{12,23}$ Inguinal hernia more on Rt. side due to later descent of Rt. testis and high incidence of patent processus vaginalis on Rt. side. ${ }^{9}$

Most elderly patients having inguinal hernia also had concomitant disease such as cardiac, pulmonary, diabetes, etc., that increased the surgical risk. ${ }^{7}$ Cardiovascular, pulmonary and urinary complications can occur after inguinal hernioplasty when performed under S/A or G/A. ${ }^{24}$ On the other hand when inguinal hernia repair is done under local anaesthesia, patients do not generally develop serious perioperative or postoperative complications. ${ }^{2}$ 
Several retrospective and randomised control trials have shown that L/A provide the best clinical and economic benefits to patients. ${ }^{25,26,27}$ In spite of all these benefits, the use of L/A in hernia repair has not been widely practised. In this study we aimed at assessing the safety and benefits of local anaesthesia in mesh hernioplasty for inguinal hernia. In our study, only 19 (19.7\%) patients had minor complications during the procedure. No patients developed L/A related anaphylaxis reaction. Hepner DL et al. (2003). ${ }^{28}$ showed $1 \%$ anaphylaxis reaction to $\mathrm{L} / \mathrm{A}$.

Pain is the main factor in postoperative mobility. Most of the patients had pain free period within six hours period postoperatively.

In this study, 16 (59.3\%) patients complained of pain within six hours postop and $11(40.7 \%)$ patients had pain after 6 hours, totalling $27(28.1 \%)$. So, it showed that almost all patient had pain free period postop within $1^{\text {st }}$ six-hour period.

The study carried out by Van Veen et al. ${ }^{29}$ also noticed that inguinal hernia repair under L/A had significantly less pain. It is highly effective in alleviating postoperative pain when used both peripheral nerve blocking technique. ${ }^{30}$ and local wound infiltration technique at fascial level. ${ }^{31}$ Young DV (1987). ${ }^{2}$ showed that lesser postoperative analgesia was required in patients operated under L/A, because most patients felt that the subsequent pain was more tolerable as it comes gradually compared with those who had their surgery performed under general or spinal anaesthesia. If $\mathrm{L} / \mathrm{A}$ is given by experienced surgeon, it is well accepted by patients. ${ }^{19}$

The residual effect of G/A, S/A such as nausea, vomiting, sedation and increased hospital stay, etc. was negligible under L/A like other studies.6,32 Present study (TAB II) also showed wound sepsis $3(3.15 \%)$, haematoma $4(4.16 \%)$, vomiting 2 (2.08\%), hypotension $1.08 \%$, no case of mesh rejection. Similar results shown by Amid PK et al. (1994). ${ }^{8}$ Kark AE et al. (1995). ${ }^{9}$ and Gionetta E et al. (1997). ${ }^{7}$ They also showed that G/A or S/A associated with higher rate of postop complications and occasional death. Urinary retention is a major problem after hernia operation as shown by Jensen et al. ${ }^{33}$ but not when done under L/A. Present study also finds only $1(1.04 \%)$ case with urinary retention.

Early postop mobilisation results in lesser morbidity and hence early discharge from hospital and early physical activities. Callesen. ${ }^{4}$ also proves in his study that L/A helps in faster mobilisation and early discharge from than other anaesthetics technique.

\section{CONCLUSION}

The Lichtenstein tension free hernioplasty under L/A opened up a new era in inguinal hernia surgery without any serious morbidity. This technique of L/A is a good choice in old, debilitating patients and offers safe, simple, cost effective and day care surgery in hernia for adult. When anaesthesia related complications, duration of hospital stay, cost-effectiveness and applicability to all patients in adult are taken into consideration, $\mathrm{L} / \mathrm{A}$ can be recommended as a safe and effective technique for inguinal hernia mesh repair.

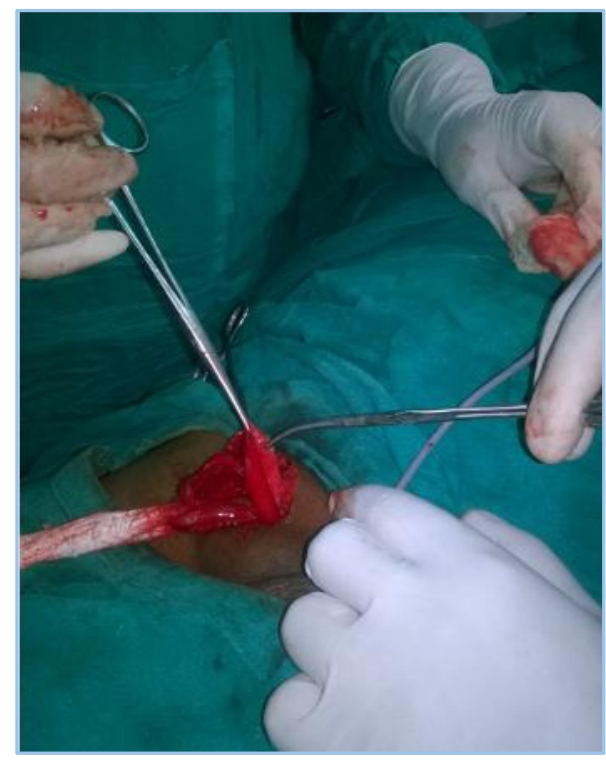

Fig. 1: Separating Hernia Sac

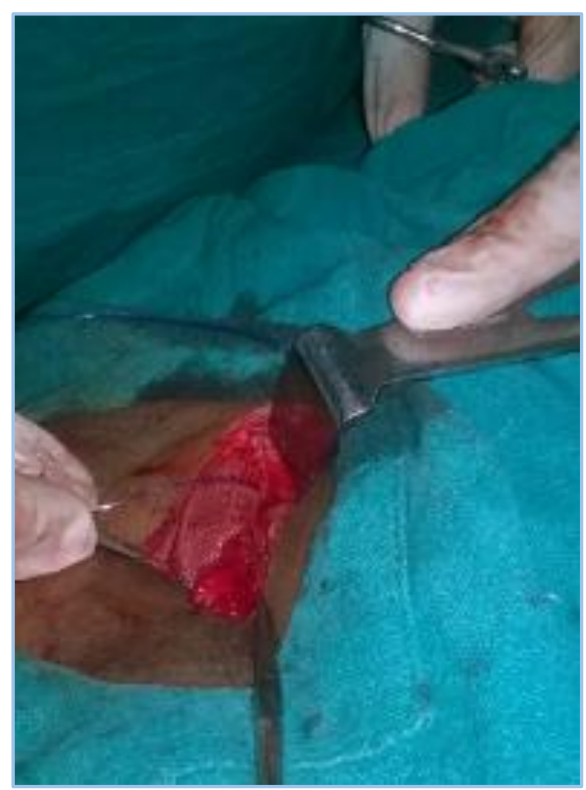

Fig. 2: Putting Hernia Mesh

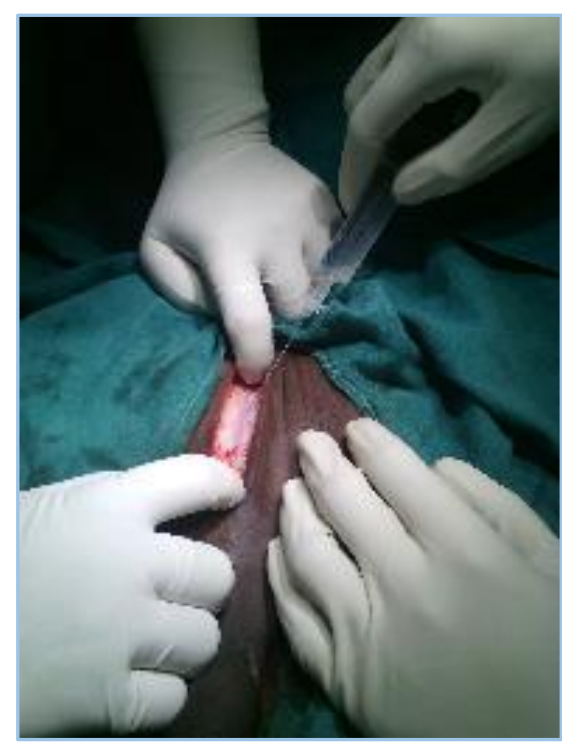

Fig. 3: Infiltrating Local Anaesthesia 


\section{REFERENCES}

1. Rutkow IM, Robbins AW. Demographic classificatory and socioeconomic aspects of hernia repair in united states. Surg Clin n Am 1993;73(3):413-26.

2. Young DV. Comparison of local, spinal and general anaesthesia for inguinal hernia. Am J Surg 1987;153:5603.

3. Amado WJ. Anaesthesia for groin hernia surgery. Surg Clin N Am 1993;73:427-38.

4. Callesen T. Inguinal hernia repair: anaesthesia, pain and convalescene. Dan Med Bull 2003;50(3):203-18.

5. Amado WJ. Anaesthesia for groin hernia surgery. Surg Clin N Am 2003;83:1065-77.

6. Callesen T, Bech K, Kehlet H. One thousand consecutive groin hernia repairs under local anaesthesia. Anaesth analg 2001;93:1373-6.

7. Gianetta E, De Cian F, Cuneo S, et al. Hernia repair in elderly patients. Br J Surg 1997;84(7):983-5.

8. Amid PK, Shulman AG, Lichenstein IL. Local anaesthesia for inguinal hernia repair step by step procedure. Ann Surg 1994;220(6):735-7.

9. Kark AE, Kurzer M, Waters KJ. Tension free mesh hernia repair, review of 1098 using local anaesthesia in a day unit. Ann R coll Engl 1995;77(4):299-304.

10. Wantz GE. Ambulatory hernia surgery. $\mathrm{Br} \mathrm{J}$ surg 1989;76(12):1228-9.

11. Callesen $T$, Bech K, Kehlet $H$. The feasibility, safety, and cost of infiltration anaesthesia for hernia repair. Anaesthesia 1998;53:31-5.

12. O' Dwyer PJ, Serpel MG, Miller K, et al. Local or general anaesthesia for open tension-free hernioplasty: a randomised trial. Ann Surg 2002;237:574-9.

13. Johanson B, Halerback B, Gilse H, et al. Laparoscopic mesh versus open preperitoneal mesh versus conventional technique for inguinal hernia repair: a randomised multicentre trial (SCUR Hernia Repair Surgery). Ann Surg 1999;230(2):225-38.

14. Robbins AW, Rutkow IM. The plug hernioplasty. Surg Clin North Am 1993;73(3):501-12.

15. Panos RG, Beck DE, Maresh JE. Preliminary results of a prospective randomised study of cooper's ligament versus shouldice herniorrhaphy technique. Surg Gnaecol Obstet 1992;175(4):315-9.

16. Hay JM, Boudet MJ, Fingerhut A, et al. Shouldice inguinal hernia repair in the male adult: the gold standard? a multicenter controlled trial in 1578 patients. Ann Surg 1995;222(6):719-22.

17. Vruland WW, van den Tol MP, Luijendijk RW, et al. Randomized clinical trial of nonmesh versus mesh repair of primary inguinal hernia. Br J Surg 2002;89(3):293-7.
18. Lichenstein IL. Hernia repair without disability. St Louis, MO: Ishiaku Euroamerica; 1987.

19. Karke AE, Kurzer MN, Belsham PA. Three thousand one hundred seventy five primary inguinal hernia repairs; advantages of ambulatory open mesh repair using local anaesthesia. Am J Coll Surg 1998;186(4):447-55.

20. Song D, Greilich NB, White PF, et al. Recovery profiles and cost of anaesthesia for outpatient unilateral inguinal herniorraphy. Anaesth Anaig 2000;91(4):876-81.

21. Ryan JA, Adye BA, Jolly PC, et al. Outpatient inguinal herniorrhaphy with both regional and local anaesthesia. Am J Surg 1984;148(3):313-6.

22. Erdem E. Comparison of local and spinal anaesthesia technique in inguinal hernia repair. Denizli Turkey: Pamulale University School of medicine 2003.

23. Stobie B. Shouldice hospital dedicated to the repair of hernias. Can Oper Room Nurs J 1999;17(4):30-2.

24. Namhe AE. Groin hernia in elderly patients. Management and prognosis. Am J Surg 1983;146(2):257-60.

25. Gonullu NN, Cubukcu A, Alpona A. Comparison of local and general anaesthesia in tension free (lichtenstein) hernioplasty: a prospective randamized trial. Hernia 2002;6(1):29-32.

26. O zgun H, Kurt MN, Kurt I, et al. Comparison of local, spinal and general anaesthesia for inguinal herniorraphy. Eur J Surg 2002;168(8-9):455-9.

27. Nordin P, Zeterstrom H, Gunarson U, et al. Local, regional or general anaesthesia in groin hernia repairs; multicentre randomized trial. Lancet 2003;362(9387):853-7.

28. Hepner DL, Castells MC. Anaphylaxis during perioperative period. Anaesth Analg 2003;97:1381-95.

29. Van Veen RN, Mahaboer C, Dawson I, et al. Spinal or local anaesthesia in lichtenstein hernia repair: a randomized control trial. Ann Surg 2008;247:428-33.

30. Ding Y, White PF. Post herniorraphy pain in outpatients after pre incision illeoinguinal-hypogastric nerve block during monitored anaesthesia care. Can J Anaesth 1995;42(1):12-5.

31. Yndgarrd S, Holst P, Bjerre-Jepsen K, et al. Subcutaneously versus subfascially administered lidocainin pain treatment after inguinal herniotomy. Anaesth analg 1994;79(2):3247.

32. Subramaiam P, Leslie J, Gourlay C, et al. Inguinal hernia repair: a comparison between local \& general anaesthesia. Aust N Z J Surg 1998;68(11):799-800.

33. Jensen $P$, Mikkelsen $T$, Kehlet $H$. Post herniorrhaphy urinary retention-effect of local, regional and general anaesthesia a review. Reg Anaesth pain Med 2002;27(6):612-7. 